\title{
Blame, culture and child protection
}

\author{
Jadwiga Leigh, 2017 \\ Palgrave Macmillan, London, UK \\ ISBN 978-1-137-47008-9, pp. 255, hardback, NZD170.00
}

$\mathrm{I}$ n recent years, the public has held social workers responsible for rescuing "atrisk" children and the media are poised to pounce when a child is seriously harmed. Sensationalist reporting has tarnished the profession's reputation, especially in England. Jadwiga Leigh's book offers an insider's perspective on what it means to be a social worker in this context. It includes stories, vignettes, observations and reflective research notes from her comparative ethnographic study of English and Flemish child protection agencies. The tone is experiential, immediate and, at times, very personal. Drawing on social interactionism and Goffman's work on stigma, Leigh discusses the nature of "profession" and "professional identity". She explains how professional decision-making is profoundly undermined by constant awareness of public scrutiny and describes the different experience of social workers in Flanders, where child welfare practice maintains a tradition of supporting families, child protection practice is interdisciplinary, compassionate and collegial, and social work is still a respected profession.

Beginning with a lament for English social workers' loss of status, Leigh explains that the profession has reacted to blame by veering towards risk avoidance, stifling the responsive, "inspirational" practice that was formerly its hallmark and undermining social workers' confidence in their specialist expertise. Social workers dread featuring on the front page of the tabloid newspapers as the person responsible for "failing" to protect a child. Faced with the dilemma of assessing whether a child is safe at home, it can feel much safer to err on the side of caution and use statutory power to take that child into care, thus both fulfilling and shaping public perceptions of the social work role. An alternative course of action is to work with the child's family to help them resolve issues considered risky but that can feel unrealistic when administrative requirements are prioritised over relationship-building, and when other sources of support are hard to find. This kind of risk-averse practice has infiltrated the child welfare field in Aotearoa New Zealand, where recent rhetoric positions children as "vulnerable" to harm because their families' problems are entrenched and intractable.

Leigh's book explains how English child protection agencies reacted to the threat of public vilification. In a rather futile attempt to insulate themselves against criticism, they adopted a defensive stance. To forestall accusations of careless monitoring, they developed hierarchical organisational structures and managerial surveillance of social workers' compliance with administrative procedures. Targets and timescales leave little scope for developing the trusting relationships that enable social workers to hear families' stories, understand their problems, and work with them towards some kind of solution. Child protection has morphed into agency protection and child protection social work has internalised risk. However, instead of protecting the social work profession from public blame and contempt, this reaction eroded the profession's reputation. Child protection social work is perceived as callous rather than helpful. Yet, rather than regaining respect by articulating the strong, cohesive body of knowledge that underpins 
the profession's specialist expertise in supporting people experiencing hard times, child protection social work has been complicit in the damage done.

Organisational culture that equates professionalism with compliance is incompatible with the values and expertise at the heart of social work's capacity to promote the well-being of children and their families, and to its capacity to promote social justice.

Leigh compares this regrettable state of affairs with the very different Flemish child welfare system which is based in an established, integrated continuum of care. The preventive end of this continuum features home-based support provided by specially trained nurses for all families with new babies, for as long as they need it. The investigative end of the continuum aims to maintain a supportive attitude. Leigh's book uses photos and descriptions to illustrate how physical environment embodies prevailing assumptions about the professional/client relationship and the status of social workers. Photographs of the English site show a bleak environment that prioritises managerial concerns about efficiency and reflects power differentials. This "fortress of social work" reflects hierarchical staffing structures by positioning social workers in an open-plan office where confidentiality is compromised and managers can keep an eye on what is going on from behind venetian blinds encasing the glass that partitions their workspaces from the common space occupied by other staff. There is no sign of any attempt to make children and families feel comfortable in the building, while obvious signage does nothing to decrease stigma.

By contrast, the Flemish agency is located in a school. Social workers meet with children and families in personalised, individual offices accessed via a corridor adorned with artwork intended to demonstrate that many families have struggled previously, and thus lessen stigma. A photo of this corridor shows artwork in the form of "coffin-shaped boxes" containing compressed paper records of work with previous families. This seems bizarre, but Leigh does not discuss other possible interpretations - an example of her tendency to report rather than analyse. Despite her focus on "how space and environment can impact on the identity of those who work in these settings and those who visit them" (p. 139), she does not probe the incongruity between the agency's professed aims and its practice. For example, students are excluded from the staff lunchroom despite the agency's commitment to collegiality.

Leigh's comparative ethnography leaves crucial questions unanswered. How realistic is it to imagine shifting individualised child protection practice typical of riskaverse cultures towards the collegial, interdisciplinary work and collective responsibility that characterises the work of the Flemish agency described in Leigh's book? To what extent is it possible for a statutory agency to engage in supportive practice when families view social workers as authoritarian? Deep-seated suspicion of English social workers' motives and competence is implicit in some of the stories presented in the book. Such suspicion builds over many years and will not easily dissipate, so how could the English child protection model metamorphose into something resembling the Flemish model? The book's discussion of entrenched risk-averse orientation suggests that metamorphosis could not happen without a fundamental change in the way child protection agencies view, value and support their social workers. Transformation to a less mechanistic culture would require significant attitudinal change, a shift away from the prevailing view that it is imperative to rescue children from families deemed dangerous and towards supporting families to raise their children safely. Flemish child protection builds on universal, preventive service provision, inter-professional respect and collective responsibility. Unfortunately, preventive services in Aotearoa New Zealand 
have also been eroded and collegial practice is not well developed.

The experiences described in Leigh's book will resonate with many social workers. This may be helpful to those struggling with a sense of dissonance between what they entered social work to do and what they find themselves doing. The book's description of a sustained comparative ethnography project will be useful to people contemplating research projects using similar methodology. Where it may be especially useful, however, is in helping outsiders understand the quandaries and constraints routinely encountered by child protection social workers. The book provides vivid extracts from social workers' accounts of their professional lives and thus offers insight into the realities of practice, including anxieties, regrets and disappointments that now characterise the child protection field. Although social workers may not be encouraged by the book's content, it could potentially counteract the media's propensity to denigrate social work. If the book were required reading for journalism students, they might more carefully consider the moral dimension of their own future work. Mostly, however, the book points to the need for social workers to take control of the narrative about what social work can, and should, do. 